\title{
Recombinant protein production by large-scale transient gene expression in mammalian cells: state of the art and future perspectives
}

\author{
Lucia Baldi · David L. Hacker · Myriam Adam • \\ Florian M. Wurm
}

Received: 2 November 2006/Revised: 19 December 2006/ Accepted: 21 December $2006 /$

Published online: 19 January 2007

(C) Springer Science+Business Media B.V. 2007

\begin{abstract}
The expansion of the biologics pipeline depends on the identification of candidate proteins for clinical trials. Speed is one of the critical issues, and the rapid production of high quality, research-grade material for preclinical studies by transient gene expression (TGE) is addressing this factor in an impressive way: following DNA transfection, the production phase for TGE is usually $2-10$ days. Recombinant proteins (r-proteins) produced by TGE can therefore enter the drug development and screening process in a very short time-weeks. With "classical" approaches to protein expression from mammalian cells, it takes months to establish a productive host cell line. This article summarizes efforts in industry and academia to use TGE to produce tens to hundreds of milligrams of $r$ proteins for either fundamental research or preclinical studies.
\end{abstract}

Keywords Mammalian cells · Non-viral gene delivery $\cdot$ Recombinant protein - Transient gene expression

L. Baldi $(\bowtie) \cdot$ D. L. Hacker $\cdot$ M. Adam .

F. M. Wurm

Laboratory of Cellular Biotechnology, Ecole

Polytechnique Fédérale de Lausanne, Station 6, 1015

Lausanne, Switzerland

e-mail: Lucia.Baldi@epfl.ch

\section{Introduction}

The production of recombinant proteins (r-proteins) has been an important technology over the last twenty years with the main focus being on biopharmaceutical products with medical applications. Most r-proteins in this category are complex molecules that need to be post-translationally modified for full bioactivity. As such modifications are only accurately performed by mammalian cells, they have become the major host for complex r-protein expression (Wurm 2004). Pharmaceutical companies routinely establish recombinant cell lines that constitutively produce r-proteins for extended cultivation times. This stable gene expression is achieved through the insertion of the recombinant gene(s) into the host genome. However, identification and characterization of recombinant cell lines is a costly and time-consuming process. Faster approaches to r-protein production are sometimes preferred when one must rapidly evaluate many candidate proteins or when several variants of a single protein need to be studied for their potential as biologics. Transient gene expression (TGE) is well-suited to fill this need. In contrast to stable gene expression, TGE involves short-term rprotein production typically for up to 10 days post-transfection in the absence of genetic selection of the plasmid DNA. Secreted, membrane, and intracellular proteins have been successfully 
expressed by TGE (Meissner et al. 2001; Geisse and Henke 2005; Shi et al. 2005), and highthroughput approaches for TGE in human embryonic kidney (HEK 293) cells have recently been described for the production of G-protein coupled receptors (Davies et al. 2005). This review emphasizes the main advantages and drawbacks of large-scale TGE performed with suspension cultures of mammalian cells (the term "large scale" is implied for work with cultures greater than 11 in working volume) and describes challenges for further improvement of the technology.

\section{Expression vectors}

Different expression vectors, both non-viral and viral, have been designed to transfer foreign genes into mammalian cells. The choice of the vector depends on the application, the host cell, the time limitation, the level of desired product, and safety. Only a brief overview of this subject is provided here. Additional information may be found in recent reviews (Makrides 1999; Van Craenenbroeck et al. 2000).

\section{Non-viral expression vectors}

Essential elements of typical TGE vectors include (1) a constitutive or inducible promoter; (2) a transcription terminator; and (3) a prokaryotic cassette with a replication origin and a selection marker for vector production in bacteria. Most of the commonly used strong constitutive promoters are from viral genomes including the human cytomegalovirus (HCMV) immediate early promoter, the simian virus 40 (SV40) early promoter, and Rous sarcoma virus long-terminal repeat promoter. Cellular promoters such as that of the human elongation factor-1-alpha $(\mathrm{EF}-1 \alpha)$ gene have been shown to be similar in strength to the HCMV promoter (Gill et al. 2001). Although most cDNAs can be expressed at high levels from a strong constitutive promoter, insertion of an intron between the promoter and the $5^{\prime}$-end of the cDNA has been shown to increase the r-protein expression level (Buchman and Berg 1988). Mammalian cells expressing the Epstein-
Barr virus (EBV) nuclear antigen 1 (EBNA1) or the SV40 large-T antigen, support the episomal amplification of vectors carrying the EBV or the SV40 origin of replication, respectively. This strategy improves r-protein production levels by increasing the plasmid copy number in the transfected cell population (Van Craenenbroeck et al. 2000; Young et al. 1988).

TGE requires a significant amount of plasmid DNA. Typical protocols use about $1-1.25 \mu \mathrm{g}$ plasmid DNA per ml culture. DNA is thus a major cost-factor for large-scale TGE. Two of the most important aspects of the plasmid purification are the recovery of a high percentage of supercoiled DNA and the elimination of contaminants such as bacterial RNA and endotoxin (Stadler et al. 2004). Although it has been reported that these contaminants do not significantly affect the efficiency of transfection with the calcium phosphate (CaPi) method (Wright et al. 2003), the removal of lipopolysaccharide (LPS) is critical in downstream processing of the r-protein (Wakelin et al. 2006).

\section{Viral expression vectors}

Semliki Forest virus (SFV) is the most widely used viral expression vector for TGE. Large-scale production of a recombinant G-protein coupled receptor has been performed with SFV-infected mammalian cells cultured in suspension in bioreactors or spinner flasks (Blasey et al. 2000; Hassaine et al. 2006). Baculovirus vectors have also been used to produce r-proteins in both insect and mammalian cells (Boyce and Bucher 1996; Hofmann et al. 1995; Kost et al. 2000). The disadvantage of using insect cells is that they are unable to produce fully active recombinant mammalian glycoproteins due to the absence of sialylation. Thus, efforts have been made to engineer baculovirus expression systems that allow production of humanized recombinant glycoproteins in insect cells (Jarvis 2003; Seo et al. 2001). For the expression of r-proteins in mammalian cells, baculovirus vectors have numerous advantages including: (1) the absence of viral replication, (2) the lack of cytotoxicity, (3) the technical simplicity of vector production, and (4) the large DNA insert capacity (up to $38 \mathrm{~kb}$ ) 
allowing the delivery of multiple genes from a single vector (Kost et al. 2000). Finally, vaccinia virus vectors have been used to produce $r$ proteins such as nerve growth factor (Edwards et al. 1988), Factor VIII (Pavirani et al. 1987), and human pro-thrombin (Falkner et al. 1992). The infectious nature of the virus is a major concern, and it requires containment in a Biosafety Level 2 laboratory. To reduce safety risks, less infectious strains such as the modified vaccinia virus Ankara (MVA) have been used (Sutter and Moss 1992).

\section{Non-viral gene delivery vehicles}

A multitude of physical and chemical methods have been developed for the transfer of DNA into cultivated mammalian cells, but only a few of these are applicable to large-scale TGE. In general, the chemical agents used for transfection can be classified into inorganic compounds, cationic polymers, and cationic lipids. Among the methods employing inorganic compounds, $\mathrm{CaPi}$ DNA coprecipitation is still the most widely used (Jordan et al. 1996). The most efficient cationic polymers are polyethylenimines (PEIs), most notably either branched or linear $25 \mathrm{kDa}$ PEI (Boussif et al. 1995; Thomas and Klibanov 2003). Even though cationic lipids are very effective transfection agents, they have not been frequently used for large-scale TGE due to the comparatively high cost. All of these chemical agents face the same barriers regarding the delivery of functional DNA into the nucleus of cells (Lechardeur et al. 2005). Physical gene transfer methods such as microinjection, electroporation, and ballistics bypass these cellular barriers and deliver naked plasmid DNA directly to the nucleus. However, these methods have not been successfully adapted to large-scale TGE.

$\mathrm{CaPi}$ remains one of the most efficient DNA delivery agents, as it allows transfer of plasmid DNA to approximately 80-90\% HEK 293 cells under some conditions (Meissner et al. 2001). Although it is inexpensive and does not interfere with protein recovery, there are several drawbacks to its use including the time-sensitive formation of the coprecipitate, making transfection of large volumes technically challenging. The requirement for serum in the transfection medium to limit the "growth" or aggregation of the coprecipitate into large inefficient complexes is another critical constraint. Furthermore, $\mathrm{CaPi}$ is not an efficient delivery method for chinese hamster ovary $(\mathrm{CHO})$ cells without an osmotic shock (Batard et al. 2001). In a variation of the traditional CaPi method, Lindell et al. (2004) demonstrated that addition of DNA and $\mathrm{CaCl} 2$ directly to a suspension culture of HEK 293 cells ("Calfection") resulted in the production of about $3 \mathrm{mg} / \mathrm{l}$ antibody in a 301 culture.

Currently, the most widely used DNA delivery agent for large-scale TGE appears to be PEI. Transfections with linear $25 \mathrm{kDa}$ PEI have been the most productive to date with reported IgG yields up to $80 \mathrm{mg} / \mathrm{l}$ in HEK 293 cells (Wuhlfard and Wurm, unpublished results) and $22 \mathrm{mg} / \mathrm{l}$ in CHO cells (Muller 2005) (see Table 1). PEI is moderately cytotoxic and non-biodegradable. Importantly, the effects of residual PEI on the downstream processing of r-proteins and on $r$ protein quality have not been systematically addressed.

\section{Large-scale TGE}

Cell lines

Several cell lines have been used for transient expression of r-proteins, but only a few of them present the advantages of (1) high transfectability with common methods (2) ease of adaptation to suspension cultivation in serum-free conditions, and (3) cost-effective scalability. HEK 293 is the most commonly used cell line for large-scale transient transfection. It was created nearly 30 years ago by transformation of primary human embryonic kidney cells with sheared fragments of adenoviral DNA (Ad5) (Graham et al. 1977), and they constitutively express the adenovirus E1A and E1B genes. In order to support large-scale adenovirus production in bioreactor cultures, this cell line was adapted to suspension growth, and the resulting cell line was named 293N3S 
Table 1 Transient expression of recombinant proteins at scale of more than 11 final volume

\begin{tabular}{|c|c|c|c|c|c|c|c|c|}
\hline Product & Cells & $\begin{array}{l}\text { Transfection } \\
\text { agent }\end{array}$ & Serum & $\begin{array}{l}\text { Scale } \\
\text { (litre) }\end{array}$ & $\begin{array}{l}\text { Culture } \\
\text { system }\end{array}$ & $\begin{array}{l}\text { Maximum titer } \\
(\mathrm{mg} / \mathrm{L})\end{array}$ & $\begin{array}{l}\text { Maximum } \\
\text { yield (mg) }\end{array}$ & Reference \\
\hline $\begin{array}{l}\text { TNF- } \\
\text { Rp55 }\end{array}$ & HEK293E & PEI & no & 2 & Erlenmeyer & 0.55 & n.d. & $\begin{array}{l}\text { Schläger and } \\
\text { Christensen (1999) }\end{array}$ \\
\hline huIgG & HEK293E & $\mathrm{CaPi}$ & yes & 110 & $101 \mathrm{STR}$ & 7.7 & 500 & Girard et al. (2002) \\
\hline $\begin{array}{l}\text { SEAP } \\
\text { (a) }\end{array}$ & HEK293E & PEI & yes & 3.5 & $\begin{array}{l}\text { Helical } \\
\text { ribbon }\end{array}$ & 20 & 60 & $\begin{array}{l}\text { Durocher et al. } \\
(2002)\end{array}$ \\
\hline $\begin{array}{r}\text { Tie-2 } \\
\text { ED }\end{array}$ & 293-SFE & PEI & no & 14 & STR & n.d. & 33 & Pham et al. (2003) \\
\hline NP-1 & 293-SFE & PEI & no & 10 & STR & n.d. & 35 & Pham et al. (2003) \\
\hline various & HKB11 & DMRIE-C & no & 10 & Wave $^{\mathrm{TM}}$ & 40 (b) & 400 & Cho et al. (2003) \\
\hline hu-IgG & HEK293E & Calfection & yes & 30 & $1101 \mathrm{STR}$ & 2.5 & 75 & Lindell et al. (2004) \\
\hline hu-IgG & $\mathrm{CHO}(\mathrm{c})$ & PEI & no & 13 & $201 \mathrm{STR}$ & 6 & n.d. & Derouazi et al. (2004) \\
\hline SEAP & HEK293E & PEI & yes & 1 & $11 \mathrm{STR}$ & 25 & n.d. & Pham et al. (2005) \\
\hline SEAP & $\begin{array}{l}\text { HEK } \\
\text { 293F }\end{array}$ & PEI & no & 1 & $11 \mathrm{STR}$ & 10 & n.d. & Pham et al. (2005) \\
\hline$>30$ & HEK293E & PEI & no & 10 & Wave $^{\mathrm{TM}}$ & 12 & n.d. & $\begin{array}{l}\text { Geisse and Henke } \\
\text { (2005) }\end{array}$ \\
\hline various & HEK293E & PEI & no & 2 & $\begin{array}{l}\text { Shake } \\
\text { bottle }\end{array}$ & 27 & 145 & Baldi et al. (2005) \\
\hline hu-IgG & $\mathrm{CHO}(\mathrm{c})$ & PEI & no & 80 & $1101 \mathrm{STR}$ & 22 & n.d. & Muller (2005) \\
\hline $\begin{array}{c}\text { various } \\
\text { IgGs }\end{array}$ & CHO-K1s & LF (d) & no & 1 & Spinner & 20 & n.d. & Rosser et al. (2005) \\
\hline hu-IgG & HEK293E & PEI & no & 4 & Biotainer $^{\mathrm{TM}}$ & 4.25 & 17 & L. Baldi (e) \\
\hline B2- & HEK293E & PEI & no & 2 & $\begin{array}{l}\text { Shake } \\
\text { bottle }\end{array}$ & n.a. & 24 & L. Baldi (e) \\
\hline hu-IgG & $\mathrm{CHO}(\mathrm{c})$ & PEI & no & 10 & Biotainer $^{\mathrm{TM}}$ & 17.5 & n.a. & M. Stettler (e) \\
\hline hu-IgG & $\mathrm{CHO}(\mathrm{c})$ & PEI & no & 10 & Wave $^{\mathrm{TM}}$ & 9 & n.a. & M. Stettler (e) \\
\hline hu-IgG & HEK293E & PEI & no & 10 & $\begin{array}{l}\text { Shake } \\
\text { bottle }\end{array}$ & 80 & n.a. & S. Wuhlfard (e) \\
\hline
\end{tabular}

(a) and 13 other proteins; (b) only 8 over 50 proteins express at titers >10 mg/l; (c) CHO DG44 cells; (d) LF, Lipofectamine; (e) unpublished results

Abbreviations: n.d., not described; n.a., not available; DMRIE-C, 1,2-dimyristyloxypropyl-3-dimethyl-hydroxy ethyl ammonium bromide/cholesterol; STR, stirred-tank bioreactor; HEK293E, HEK 293 EBNA; 293-SFE, HEK 293 serum-free EBNA cells; HEK 293F, HEK 293 Freestyle (commercially available from Invitrogen).

(Graham 1987). Yet another cell line (293S) was generated through gradual adaptation to serumfree medium (Garnier et al. 1994). A subclone of this cell line (293SF-3F6) has been further selected for its capacity to grow at high density $\left(8 \times 10^{6}\right.$ cells $\left./ \mathrm{ml}\right)$ in serum-free suspension and is frequently used for the production of adenoviral vectors (Côté et al. 1998). In the attempt to specifically improve TGE through promoting episomal replication of the exogenous plasmid DNA, two other HEK 293 derivatives have been generated: HEK 293-T and HEK 293-EBNA that constitutively express from stably transfected gene the SV40 large $\mathrm{T}$ antigen and the EBV EBNA1 protein, respectively (see section on nonviral expression vectors). Another cell line
(HKB11) was derived from HEK 293 cells through the fusion with a human B cell lymphoma (Cho et al. 2002). This cell line was successfully used in a 101 Wave bioreactor system for TGE (see below). Recently a few groups described successful TGE in CHO cells previously adapted to serum-free suspension growth (Derouazi et al. 2004; Rosser et al. 2005). The two strains of CHO most commonly used for TGE are $\mathrm{K} 1$ and the dihydrofolate reductase mutant DG44 (Urlaub and Chasin 1980). These cells have been widely used for decades in industrial laboratories. They have a very high productivity potential and there is a well-developed understanding of their behaviour in bioprocesses. In particular, when TGE is used as screening tool for drug development, it is 
highly desirable to rapidly obtain $\mathrm{CHO}$-derived material for preclinical tests, as this will be the host cell for stable cell line development. Although there is no evidence that HEK 293derived r-proteins differ in any way from $\mathrm{CHO}$ derived material, the pharmaceutical industry prefers to use $\mathrm{CHO}$ cell lines for production because of their established track record. A few successful reports of TGE in $\mathrm{CHO}$ at large scale (larger than 11 ) are summarized in Table 1.

\section{Production media}

Due to intensive research into media formulations for the manufacture of r-proteins, serumfree cultures are now the standard for growth of mammalian cells in suspension (Barnes and Sato 1980). The need to minimize animal-derived components in production processes, both for biosafety reasons and to facilitate downstream processing, has created an interest in using protein hydrolysates (peptones) as a protein supplement to replace serum. Hence a number of chemically defined media have been developed which do not contain animal-derived material. These media generally support high cell densities and facilitate the expression and purification of $r-$ proteins. Most often these media have been developed specifically for serum-free cultivation of HEK 293 or CHO cells. Initial attempts to perform transient transfection in these serum-free media failed, mainly because of the presence of polymers that hinder transfection complex stability and uptake. Transfection in these media has then been made possible through accurate optimisation of the gene delivery protocols (Derouazi et al. 2004; Muller 2005). Supplementation of standard protein-free media with peptones yielded a significant increase in TGE productivity in HEK 293-EBNA cells (Pham et al. 2003; Pham et al. 2005).

\section{Large-scale processes}

There are only a few published reports on TGE at scales larger than 11 , and even less for 101 and more. Most of these publications have originated from academic laboratories. Large-scale processes employ mostly standard stirred-tank bioreactors (STR), but a recently developed bioreactor (the Wave ${ }^{\mathrm{TM}}$ ), with disposable plastic bags, has proven to be particularly well-suited for TGE (Geisse and Henke 2005). Disposable bioreactors are raising interest mainly due to their low initial investment cost and their ease of operation, maintenance, and validation. In addition, TGE in non-instrumented round- or square-shaped bottles of nominal volumes of $1-201$ is being explored. In head-to-head comparisons these containers have outperformed instrumented bioreactors, making them an attractive, inexpensive alternative for large-scale TGE (Wuhlfard, Hildinger, Stettler and Wurm, manuscript in preparation).

\section{Expression level}

Table 1 summarizes the publications reporting TGE at scales of 11 or more, together with a few unpublished results from our laboratory. However, several leading biopharmaceutical companies are routinely employing TGE at scales up to 1001 for their drug discovery programs.

Volumetric productivity with TGE depends to a great extent on the intrinsic structural features of the r-protein, thus it is difficult to compare the efficacy of various TGE protocols (Bentley et al. 1998). In general, with efficient non-viral gene delivery agents like PEI, titers range from 1 to $80 \mathrm{mg} / \mathrm{l}$ with either $\mathrm{CHO}$ or HEK 293 cells (Table 1). IgG yields in the range of $2-80 \mathrm{mg} / \mathrm{l}$ have been achieved in instrumented bioreactors ranging in size from 3 to 1501 using either batch or fed-batch approaches (Meissner et al. 2001; Girard et al. 2002).

\section{Conclusions and future perspectives}

The technology to generate research-quality r-proteins by TGE has been under development for more than 10 years in both academic and industrial laboratories. During this period, the major improvements in TGE have come via the formulation of serum-free media that support high-density growth of cells in suspension and efficient serum-free transfection methods. Despite these advances, the specific productivity of 
TGE remains typically far below $10 \mathrm{pg} /$ cell · day, whereas that of some recombinant cell lines has been reported to be over $50 \mathrm{pg} / \mathrm{cell}$ - day (Wurm 2004). It is therefore likely that the upper limit for the specific productivity by TGE has not yet been achieved. One of the major challenges for the future is to close the gap between transient and stable r-protein productivity. Another gap exists with respect to cell number in batch processes between transient and stable expression. Whereas most transient protocols result in cell densities below $3 \times 10^{6}$ cells $/ \mathrm{ml}$, optimized high-yield stable processes achieve $10-15 \times 10^{6}$ cells $/ \mathrm{ml}$ over 10-14 days (Wurm 2004). While the exact nature of the improvements are not known in detail for proprietary reasons, it is likely that they involve (i) the development of both serum-free and protein-free media to support high-density cultivation of cells in suspension, (ii) improved feeding strategies (for fed-batch cultures), and (iii) the genetic modification of the host cells. This results in volumetric yields of up to $5 \mathrm{~g} / \mathrm{l}$ in the best cases. Targets for cell engineering may include metabolic and apoptotic pathways (Fussenegger and Bailey 1998). For example, strategies involving the over-expression of exogenous anti-apoptotic genes have led to higher cell viability and improved r-protein yield (Mastrangelo et al. 2000; Tey et al. 2000; Kim and Lee 2002). Similar strategies are also likely to benefit TGE. As an example, it has been shown that improved transient r-protein production results from the inhibition of the cell cycle (Tait et al. 2004; Galbraith et al. 2006). To establish more efficient host cells for TGE through genetic manipulation, the overexpression of exogenous genes as mentioned above and the downregulation of host genes through siRNA technology (Hacker et al. 2004) should be attempted.

A very promising route and probably the best one for providing high volumetric yields is the increase in biomass before, during and/or after transfection. Other improvements to TGE are likely to come from the transfection process itself. All of the major chemical transfection agents used for TGE including $\mathrm{CaPi}, \mathrm{PEI}$, and liposomes have major drawbacks as described above. In addition, they only deliver a small percentage of the transfected DNA $(<10 \%)$ to cells (Batard et al. 2001; Lechardeur et al. 2005). More efficient DNA transfer would allow the amount of plasmid DNA, a major cost factor in addition to a major source of variability for TGE, to be reduced. Besides increased transfection efficiency, the ideal transfection reagent will be non-cytotoxic and will not interfere with $\mathrm{r}$ protein purification or quality. The development of novel transfection agents such as dendrimers (Lee et al. 2005), chemically-modified PEI (Thomas et al. 2005), and chitosan (Dang and Leong 2006) continues and may lead to more efficient delivery methods. Finally, it may be possible to adapt physical DNA delivery methods such as electroporation to large-scale TGE ( $\mathrm{Li}$ et al. 2002).

Another major challenge remains the establishment of TGE as a bioprocess for the manufacture of r-proteins. Currently, there are no FDA-approved r-proteins generated by TGE, probably because it appears to be a "revolutionary" approach. In our mind, there is no reason to prevent eventual approval of a TGE-based manufacturing process. For certain low-dose products such as erythropoietin (EPO) or granulocyte colony-stimulating factor (G-CSF), current TGE yields are quite sufficient to establish economically feasible processes. R-proteins used for individualized medicine could also be manufactured by TGE. This is of course not the case when considering high-dose antibody products. For these it will be necessary to increase the specific productivity, the volumetric productivity and, last but not least, the maximum operating volume for TGE. The largest volume reported for TGE is 1001 (Girard et al. 2002), and volumes from 1-100 1 are probably sufficient for the production of milligram to gram quantities of r-proteins for research or for pre-clinical studies. Larger TGE processes are undoubtedly possible, but this parameter has not been adequately explored. Besides the issue of the feasibility of scaling-up the production process, there is also concern that the product heterogeneity within a batch and from batch to batch may restrict the manufacturing potential of TGE. However, not enough detailed studies on product heterogeneity in TGE production runs have been published to make a conclusive statement on this point. 


\section{Summary}

The future challenges for the biotechnology industry require a wide-angle, integrative view spanning the cell's metabolism (from genomics to proteomics and metabolomics), innovative bioprocess engineering strategies for high-density, large-scale cell cultivation, efficient gene delivery methods, and more efficient and economical downstream recovery and analytical methods. Through such an integrated approach involving both biology and engineering, we believe that in the upcoming years specific productivity of transiently transfected mammalian cells will increase to $20-50 \mathrm{pg} / \mathrm{cell} \cdot$ day. Combined with increased process robustness, reproducibility, scalability and speed, a substantial improvement in protein yield will make TGE an option for therapeutic protein manufacturing and open a whole new chapter in industrial biotechnology.

Acknowledgments The authors wish to thank Matthieu Stettler, Sarah Wuhlfard and Markus Hildinger for sharing unpublished results. This work was partly supported by the swiss KTI/CTI (Science to Market Fund). We thank A. Kühner AG for providing cell culture incubator shakers.

\section{References}

Baldi L, Muller N, Picasso S et al (2005) Transient gene expression in suspension HEK-293 cells: application to large-scale protein production. Biotechnol Prog 21(1):148-153

Barnes D, Sato G (1980) Serum-free cell culture: a unifying approach. Cell 22(3):649-655

Batard P, Jordan M, Wurm F (2001) Transfer of high copy number plasmid into mammalian cells by calcium phosphate transfection. Gene 270(1-2):61-68

Bentley KJ, Gewert R, Harris WJ (1998) Differential efficiency of expression of humanized antibodies in transient transfected mammalian cells. Hybridoma 17(6):559-567

Blasey HD, Brethon B, Hovius R et al (2000) Large scale transient 5-HT3 receptor production with the Semliki Forest Virus Expression System. Cytotechnology 32(3):199-208

Boussif O, Lezoualc'h F, Zanta MA et al (1995) A versatile vector for gene and oligonucleotide transfer into cells in culture and in vivo: polyethylenimine. Proc Natl Acad Sci USA 92(16):7297-7301

Boyce FM, Bucher NL (1996) Baculovirus-mediated gene transfer into mammalian cells. Proc Natl Acad Sci USA 93(6):2348-2352

Buchman AR, Berg P (1988) Comparison of introndependent and intron-independent gene expression. Mol Cell Biol 8(10):4395-4405
Cho MS, Yee H et al (2002) Establishment of a human somatic hybrid cell line for recombinant protein production. J Biomed Sci 9(6 Pt 2):631-638

Cho MS, Yee H, Brown C et al (2003) Versatile expression system for rapid and stable production of recombinant proteins. Biotechnol Prog 19(1):229-232

Côté J, Garnier A, Massie B et al (1998) Serum-free production of recombinant proteins and adenoviral vectors by 293SF-3F6 cells. Biotechnol Bioeng 59(5):567-575

Dang JM, Leong KW (2006) Natural polymers for gene delivery and tissue engineering. Adv Drug Deliv Rev 58(4):487-499

Davies A, Greene A, Lullau E et al (2005) Optimisation and evaluation of a high-throughput mammalian protein expression system. Protein Expr Purif 42(1):111-121

Derouazi M, Girard P, Van Tilborgh F et al (2004) Serumfree large-scale transient transfection of $\mathrm{CHO}$ cells. Biotechnol Bioeng 87(4):537-545

Durocher Y, Perret S, Kamen A (2002) High-level and high-throughput recombinant protein production by transient transfection of suspension-growing human 293-EBNA1 cells. Nucleic Acids Res 30(2):E9

Edwards RH, Selby MJ, Garcia PD et al (1988) Processing of the native nerve growth factor precursor to form biologically active nerve growth factor. J Biol Chem 263(14):6810-6815

Falkner FG, Turecek PL, MacGillivray RT et al (1992) High level expression of active human prothrombin in a vaccinia virus expression system. Thromb Haemost 68(2):119-124

Fussenegger M, Bailey JE (1998) Molecular regulation of cell-cycle progression and apoptosis in mammalian cells: implications for biotechnology. Biotechnol Prog 14(6):807-833

Galbraith DJ, Tait AS, Racher AJ et al (2006) Control of culture environment for improved polyethyleniminemediated transient production of recombinant monoclonal antibodies by $\mathrm{CHO}$ cells. Biotechnol Prog 22(3):753-762

Garnier A, Côté J, Nadeau I et al (1994) Scale-up of the adenovirus expression system for the production of recombinant protein in human $293 \mathrm{~S}$ cells. Cytotechnology 15(1-3):145-155

Geisse S, Henke M (2005) Large-scale transient transfection of mammalian cells: a newly emerging attractive option for recombinant protein production. J Struct Funct Genomics 6(2-3):165-170

Gill DR, Smyth SE, Goddard CA et al (2001) Increased persistence of lung gene expression using plasmids containing the ubiquitin $\mathrm{C}$ or elongation factor 1alpha promoter. Gene Ther 8(20):1539-1546

Girard P, Derouazi M, Baumgartner G et al (2002) 100liter transient transfection. Cytotechnology 38:15-21

Graham FL, Smiley J, Russell WC et al (1977) Characteristics of a human cell line transformed by DNA from human adenovirus type 5. J Gen Virol 36(1):5974

Graham FL (1987) Growth of 293 cells in suspension culture. J Gen Virol 68(Pt 3):937-940 
Hacker DL, Bertschinger M, Baldi L et al (2004) Reduction of adenovirus E1A mRNA by RNAi results in enhanced recombinant protein expression in transiently transfected HEK293 cells. Gene 341:227-234

Hassaine G, Wagner R, Kempf J et al (2006) Semliki Forest virus vectors for overexpression of $101 \mathrm{G}$ protein-coupled receptors in mammalian host cells. Protein Expr Purif 45(2):343-351

Hofmann C, Sandig V, Jennings G et al (1995) Efficient gene transfer into human hepatocytes by baculovirus vectors. Proc Natl Acad Sci USA 92(22):10099-10103

Jarvis DL (2003) Developing baculovirus-insect cell expression systems for humanized recombinant glycoprotein production. Virology 310(1):1-7

Jordan M, Schallhorn A, Wurm FM (1996) Transfecting mammalian cells: optimization of critical parameters affecting calcium-phosphate precipitate formation. Nucleic Acids Res 24(4):596-601

Kim NS, Lee GM (2002) Response of recombinant Chinese hamster ovary cells to hyperosmotic pressure: effect of Bcl-2 overexpression. J Biotechnol 95(3):237-248

Kost TA, Klein JL, Condreay JP (2000) Application of Recombinant Baculoviruses in Biopharmaceutical Research. In: Al-Rubeai M, Fussenegger M (eds) Cell engineering, Kluwer Academic Publishers

Lechardeur D, Verkman AS, Lukacs GL (2005) Intracellular routing of plasmid DNA during non-viral gene transfer. Adv Drug Deliv Rev 57(5):755-767

Lee CC, MacKay JA, Frechet JM et al (2005) Designing dendrimers for biological applications. Nat Biotechnol 23(12):1517-1526

Li LH, Shivakumar R, Feller S et al (2002) Highly efficient, large volume flow electroporation. Technol Cancer Res Treat 1(5):341-350

Lindell J, Girard P, Muller N et al (2004) Calfection: a novel gene transfer method for suspension cells. Biochim Biophys Acta 1676(2):155-161

Makrides SC (1999) Components of vectors for gene transfer and expression in mammalian cells. Protein Expr Purif 17(2):183-202

Mastrangelo AJ, Hardwick JM, Zou S et al (2000) Part II. Overexpression of bcl-2 family members enhances survival of mammalian cells in response to various culture insults. Biotechnol Bioeng 67(5):555-564

Meissner P, Pick H, Kulangara A et al (2001) Transient gene expression: recombinant protein production with suspension-adapted HEK293-EBNA cells. Biotechnol Bioeng 75(2):197-203

Muller N (2005) Transient gene expression for rapid protein production: studies \& optimizations under serum-free conditions. Dissertation, Ècole Polytechnique Fédérale de Lausanne

Pavirani A, Meulien P, Harrer H et al (1987) Two independent domains of factor VIII co-expressed using recombinant vaccinia viruses have procoagulant activity. Biochem Biophys Res Commun 145(1):234-240

Pham PL, Perret S, Doan HC et al (2003) Large-scale transient transfection of serum-free suspension-growing HEK293 EBNA1 cells: peptone additives improve cell growth and transfection efficiency. Biotechnol Bioeng 84(3):332-342
Pham PL, Perret S, Cass B et al (2005) Transient gene expression in HEK293 cells: peptone addition posttransfection improves recombinant protein synthesis. Biotechnol Bioeng 90(3):332-344

Rosser MP, Xia W, Hartsell S et al (2005) Transient transfection of CHO-K1-S using serum-free medium in suspension: a rapid mammalian protein expression system. Protein Expr Purif 40(2):237-243

Schlaeger EJ, Christensen K (1999) Transient gene expression in mammalian cells grown in serum-free suspension culture. Cytotechnology 30:71-83

Seo NS, Hollister JR, Jarvis DL (2001) Mammalian glycosyltransferase expression allows sialoglycoprotein production by baculovirus-infected insect cells. Protein Expr Purif 22(2):234-241

Shi C, Shin YO, Hanson J et al (2005) Purification and characterization of a recombinant G-protein-coupled receptor, Saccharomyces cerevisiae Ste2p, transiently expressed in HEK293 EBNA1 cells. Biochemistry 44(48):15705-15714

Stadler J, Lemmens R, Nyhammar T (2004) Plasmid DNA purification. J Gene Med 6 Supply 1:S54-S66

Sutter G, Moss B (1992) Nonreplicating vaccinia vector efficiently expresses recombinant genes. Proc Natl Acad Sci USA 89(22):10847-10851

Tait AS, Brown CJ, Galbraith DJ et al (2004) Transient production of recombinant proteins by Chinese hamster ovary cells using polyethyleneimine/DNA complexes in combination with microtubule disrupting anti-mitotic agents. Biotechnol Bioeng 88(6):707-721

Tey BT, Singh RP, Piredda L et al (2000) Influence of bcl-2 on cell death during the cultivation of a Chinese hamster ovary cell line expressing a chimeric antibody. Biotechnol Bioeng 68(1):31-43

Thomas M, Klibanov AM (2003) Non-viral gene therapy: polycation-mediated DNA delivery. Appl Microbiol Biotechnol 62(1):27-34

Thomas M, Lu JJ, Ge Q et al (2005) Full deacylation of polyethylenimine dramatically boosts its gene delivery efficiency and specificity to mouse lung. Proc Natl Acad Sci USA 102(16):5679-5684

Urlaub G, Chasin LA (1980) Isolation of Chinese hamster cell mutants deficient in dihydrofolate reductase activity. Proc Natl Acad Sci USA 77(7):4216-4220

Van Craenenbroeck K, Vanhoenacker P, Haegeman G (2000) Episomal vectors for gene expression in mammalian cells. Eur J Biochem 267(18):5665-5678

Wakelin SJ, Sabroe I, Gregory CD et al (2006) "Dirty little secrets"-Endotoxin contamination of recombinant proteins. Immunol Lett 106(1):1-7

Wright JL, Jordan M, Wurm FM (2003) Transfection of partially purified plasmid DNA for high level transient protein expression in HEK293-EBNA cells. J Biotechnol 102(3):211-221

Wurm FM (2004) Production of recombinant protein therapeutics in cultivated mammalian cells. Nat Biotechnol 22(11):1393-1398

Young JM, Cheadle C, Foulke JJS et al (1988) Utilization of an Epstein-Barr virus replicon as a eukaryotic expression vector. Gene 62(2):171-185 